\title{
LETTER
}

\section{Porcine blood and surrogate markers do not prove benefit of aDabi-Fab}

\author{
Nicholas J Connors ${ }^{1 *}$, Justin Gill ${ }^{2}$, Allison Nakanishi ${ }^{2}$ and Robert S Hoffman ${ }^{1}$ \\ See related research by Grottke et al., http://ccforum.com/content/18/1/R27
}

While we read with great interest the recent report concerning the reversal of dabigatran-induced coagulopathy [1], we are concerned that methodological issues limit the validity of the authors' conclusions. Firstly, it is unclear why a porcine model was utilized. Although there is clinical relevance for testing reversal agents in a trauma model, all agents were administered ex vivo. Furthermore, the established correlation between the activated partial thromboplastin time (aPTT) and dabigatran concentrations in humans [2] is absent in the pig model. Potentially, porcine coagulation pa- rameters respond to dabigatran and its reversal differently than humans. Most importantly, only surrogate markers of coagulation were reported. Having created a hemorrhagic shock model, the authors should have tested either survival or blood loss following in vivo reversal along similar lines of investigation as their prior model [3].

Since further study is needed to determine the usefulness of aDabi-Fab, we would recommend that ex vivo studies use human blood while animal studies focus on endpoints that have clear clinical relevance.

\section{Authors' response}

Oliver Grottke, Joanne van Ryn, Henri MH Spronk and Rolf Rossaint

We thank the authors for their interest in our article [1]. We chose a porcine model to facilitate investigation of dabigatran reversal using several different agents at different concentrations, in blood samples taken both before and after trauma. This method was chosen mainly for ethical reasons, to provide a basis for subsequent in vivo studies. Ex vivo studies in humans were considered, but in that setting blood would probably be spiked with dabigatran and the effects of coagulation status changes following trauma (for example, hypofibrinogenemia) could not be evaluated. Clinically relevant endpoints such as blood loss are clearly more important than laboratory data and results from a porcine model may not be reflected in human patients. These limitations are acknowledged within our article.

Our article [1] presents our first investigations of dabigatran reversal, including the preliminary dose-finding work required to proceed with in vivo studies. Using a similar

\footnotetext{
* Correspondence: nicholasconnors@gmail.com

'Division of Medical Toxicology, Department of Emergency Medicine, New York University School of Medicine, 450 First Avenue, Room 123, New York, NY 10016, USA

Full list of author information is available at the end of the article
}

porcine model of trauma, we now have initial in vivo results [4]. A prothrombin complex concentrate dose of $50 \mathrm{IU} / \mathrm{kg}$ was effective in reducing total blood loss and increasing survival. This indicates that our ex vivo data are applicable in vivo.

We disagree that correlation between aPTT and dabigatran concentration is absent in the porcine model. Sensitivity to dabigatran may be different in porcine versus human plasma, and our data suggest that the aPTT-dabigatran concentration curve is less steep in pigs than in humans when using actin FS (Dade Behring, Germany). However, as shown by the results of our study [1], aPTT is prolonged with increasing levels of dabigatran in pigs.

Abbreviation

aPTT: activated partial thromboplastin time.

\section{Competing interests}

OG has received research funding from Novo Nordisk, Biotest, CSL Behring, Nycomed. He has also received honoraria for consultancy and/or travel support from Bayer Healthcare, Boehringer Ingelheim and CSL Behring. RR has received honoraria for lectures and consultancy from CSL Behring and Novo Nordisk. JvR is an employee of Boehringer Ingelheim Pharma GmbH \& Co., Germany. HMHS has received research funding from Boehringer Ingelheim and honoraria for consultancy from Bayer. 


\section{Author details}

'Division of Medical Toxicology, Department of Emergency Medicine, New York University School of Medicine, 450 First Avenue, Room 123, New York, NY 10016, USA. ${ }^{2}$ University of British Columbia Faculty of Medicine, 317-2194 Health Sciences Mall, Vancouver, BC V6T 1Z3, Canada.

\section{Published: 17 Jun 2014}

\section{References}

1. Grottke O, van Ryn J, Spronk HM, Rossaint R: Prothrombin complex concentrates and a specific antidote to dabigatran are effective ex-vivo in reversing the effects of dabigatran in an anticoagulation/liver trauma experimental model. Crit Care 2014, 18:R27.

2. Dager WE, Gosselin RC, Kitchen S, Dwyre D: Dabigatran effects of the international normalized ratio, activated partial thromboplastin time, thrombin time, and fibrinogen: a multicenter, in vitro study. Ann Pharmacother 2012, 46:1627-1636.

3. Pragst I, Zeitler SH, Doerr B, Kaspereit FJ, Herzog E, Dickneite G, van Ryn J: Reversal of dabigatran anticoagulation by prothrombin complex concentrate (Beriplex P/N) in a rabbit model. J Thromb Haemost 2012, 10:1841-1848.

4. Honickel M, van Ryn J, Spronk HM, Ten Cate H, Rossaint R, Grottke O Prothrombin complex concentrate restores haemostasis in a dabigatran anticoagulated polytrauma pig model. Crit Care 2014, 18:S40.

$10.1186 / \operatorname{cc} 13927$

Cite this article as: Connors et al:: Porcine blood and surrogate markers do not prove benefit of aDabi-Fab. Critical Care 2014, 18:435 